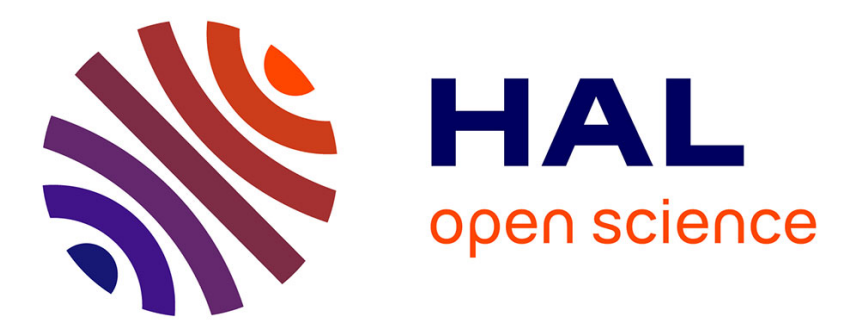

\title{
Performances of a pulsed tunable infrared raman laser for spectroscopy
}

Ph. Brechignac, S. de Benedictis, Nguyen Dai Hung, N. Halberstadt

\section{To cite this version:}

Ph. Brechignac, S. de Benedictis, Nguyen Dai Hung, N. Halberstadt. Performances of a pulsed tunable infrared raman laser for spectroscopy. Revue de Physique Appliquée, 1986, 21 (11), pp.735739. 10.1051/rphysap:019860021011073500 . jpa-00245494

\section{HAL Id: jpa-00245494 https://hal.science/jpa-00245494}

Submitted on 1 Jan 1986

HAL is a multi-disciplinary open access archive for the deposit and dissemination of scientific research documents, whether they are published or not. The documents may come from teaching and research institutions in France or abroad, or from public or private research centers.
L'archive ouverte pluridisciplinaire HAL, est destinée au dépôt et à la diffusion de documents scientifiques de niveau recherche, publiés ou non, émanant des établissements d'enseignement et de recherche français ou étrangers, des laboratoires publics ou privés. 
Classification

Physics Abstracts

$07.65 \mathrm{G}-42.65 \mathrm{C}$

\title{
Performances of a pulsed tunable infrared raman laser for spectroscopy
}

\author{
Ph. Brechignac, S. De Benedictis (*), Nguyen Dai Hung (**) and N. Halberstadt \\ Laboratoire de Photophysique Moléculaire du CNRS (***), Bâtiment 213, Université de Paris-Sud, 91405 \\ Orsay Cedex, France
}

(Reçu le 24 avril 1986, révisé le 10 juillet 1986)

\begin{abstract}
Résumé. - On décrit un laser infrarouge pulsé puissant et largement accordable. Grâce au déplacement de fréquence vers le rouge produit par diffusion Raman stimulée, l'accordabilité d'un laser à colorant pompé par un laser Nd : YAG a été transférée dans l'infrarouge moyen en sélectionnant la troisième onde Stokes sortant d'une cuve Raman capillaire. Le domaine d'accord dans l'infrarouge couvre de manière continue la plage $2 \mu \mathrm{m}-6 \mu \mathrm{m}$ pour différents colorants (oscillant dans la plage $570 \mathrm{~nm}-707 \mathrm{~nm}$ ) pompés par le rayonnement à $532 \mathrm{~nm}$. L'énergie par impulsion est de l'ordre de $1 \mathrm{~mJ}$ autour de $2 \mu \mathrm{m}$ (partant d'un laser à colorant d'environ $100 \mathrm{~mJ})$. Ce laser accordable a été testé dans des applications spectroscopiques, à partir des spectres d'absorption de quelques espèces sélectionnées, notamment $\mathrm{CH}_{4}\left(\nu_{3}\right)$ et $\mathrm{NO}(2-0)$. La largeur de raie effective est de l'ordre de $0,35 \mathrm{~cm}^{-1}$. La bande $\nu_{4}$ à $1789 \mathrm{~cm}^{-1}$ du dimère (NO) ${ }_{2}$ a également été enregistrée à l'aide d'une cuve d'absorption refroidie à $110 \mathrm{~K}$.

Abstract. - A powerful pulsed widely tunable infrared laser is described. Using the frequency red-shift provided by the stimulated Raman effect in high pressure gaseous hydrogen, the tunability of a Nd : YAG pumped dye laser has been converted down to the mid-infrared range by filtering the third Stokes wave coming out of a capillary Raman cell. Using different dyes pumped by the $532 \mathrm{~nm}$ radiation, oscillating from $570 \mathrm{~nm}$ to $707 \mathrm{~nm}$, the range of tunability in the infrared extends from $2 \mu \mathrm{m}$ up to $6 \mu \mathrm{m}$ continuously. The pulse energy level goes up to ca. $1 \mathrm{~mJ}$ near $2 \mu \mathrm{m}$ (starting from a ca. $100 \mathrm{~mJ}$ dye laser). This tunable laser has been tested for spectroscopic applications, using the absorption spectra of a few selected species, including $\mathrm{CH}_{4}\left(\nu_{3}\right)$ and $\mathrm{NO}(2-0)$. The effective linewidth is close to $0.35 \mathrm{~cm}^{-1}$. The $\nu_{4}$ band at $1789 \mathrm{~cm}^{-1}$ of the dimer (NO) ${ }_{2}$ has also been recorded using an absorption cell cooled down to $110 \mathrm{~K}$.
\end{abstract}

\section{Introduction.}

Experimental investigation of molecular relaxation or photochemical processes often requires the use of high power infrared (IR) lasers. Many studies making use of conventional molecular lasers have been reported. But the unability of such lasers to be continuously wavelength-tuned is a major limitation to such studies. This explains why efforts are being made to develop new tunable laser sources in the IR region, such like optical parametric oscillator (OPO) [1] or colour centre lasers [2]. However the wavelength domain covered by these devices is presently limited by the optical properties of the solid materials which are used. Another possibility to obtain conti-

(*) Permanent address : Centro di Studio per la Chimica dei Plasmi, Università di Bari, 70126 Bari, Italy.

(**) Permanent address : Institute of Physics, Academy of Sciences, Hanoi, Vietnam.

(***) Laboratoire associé à l'Université de Paris-Sud. nuously tunable radiation in the IR is to produce a red-shift frequency conversion of the visible radiation emitted by a high power dye laser, owing to the stimulated Raman scattering in molecular gases [36]. Such Raman lasers have already been used for molecular physics measurements in the near IR [7, 8]. We report here about the performances of a pulsed tunable Raman laser which can be wavelength-tuned continuously from the visible up to $6 \mu \mathrm{m}$.

The characteristics of a Raman laser basically depend on both the pump laser and the Raman active medium. Molecular hydrogen is known to have the largest vibrational frequency and a reasonably large Raman cross section [5]. It is then wellsuited for obtaining large frequency-shifts. Consecutive Stokes scattering can be achieved if the incident power density of the pump laser is strong enough. The large $12465 \mathrm{~cm}^{-1}=3 \times 4155 \mathrm{~cm}^{-1}$ red-shift is thus obtained by frequency down-conversion of the pump (P) radiation into the third Stokes wave $\left(S_{3}\right)$, according to two competitive mechanisms: 
i) cascading Stokes scattering [4] with $\hbar \omega_{S_{1}}=$ $\hbar \omega_{\mathrm{P}}-\hbar \omega_{\mathrm{v}} ; \hbar \omega_{\mathrm{S}_{2}}=\hbar \omega_{\mathrm{S}_{1}}-\hbar \omega_{\mathrm{V}} ; \hbar \omega_{\mathrm{S}_{3}}=\hbar \omega_{\mathrm{S}_{2}}-\hbar \omega_{\mathrm{V}}$ where $\omega_{\mathrm{V}}$ is the Raman shift.

ii) parametric four-wave mixing mechanism [9] with $\hbar \omega_{\mathrm{S}_{3}}=2 \hbar \omega_{\mathrm{s}_{2}}-\hbar \omega_{\mathrm{s}_{1}}$.

The frequency conversion efficiency depends through the Raman gain coefficients $[5,10]$ upon the molecular density of the Raman medium, the frequency of the pump laser, the interaction length, the divergence and diffraction properties of the pump and Stokes beams. We have made investigations with our experimental set-up in order to optimize the operation in the $2-6 \mu \mathrm{m}$ range as a tool for photochemical applications. We present below the details of this set-up first and the characteristics of the Raman laser, then a few spectroscopic applications to illustrate the capabilities of the apparatus.

\section{The Raman laser.}

2.1 SET-UP. - A block diagram of the laser configuration is shown in figure $1 \mathrm{a}$. The frequency-doubled output $(532 \mathrm{~nm})$ of a commercial Nd-YAG laser (Quantel YG 481-20), delivering $12 \mathrm{~ns}$ pulses of ca. $300 \mathrm{~mJ}(532 \mathrm{~nm})$ at a repetition rate of $20 \mathrm{~Hz}$, is used to pump a tunable dye laser (Quantel TDL III). The energy output of the dye laser with 3-stages amplification is ca. $100 \mathrm{~mJ}$ in the case of Rh6G. Its beam is used to pump the $\mathrm{H}_{2}$ Raman medium contained in a $1.5 \mathrm{~m}$ long, $10 \mathrm{~mm}$ i.d. stainless steel cell designed for high pressures. The two fitting parts hold respectively the silica input window oriented at Brewster's angle and the normal incidence $\mathrm{CaF}_{2}$ output window. The central portion allows for the introduction of a capillary pyrex tube working as a dielectric waveguide $[11,6]$. This permits to obtain a long interaction zone with a high power density and simultaneous reduction of the diffraction losses from the pump and Stokes laser beams. By this technique Hartig and Schmidt have achieved an efficient energy conversion to the $\mathrm{S}_{3}$ component, which they interpreted as due to the four-wave mixing mechanism [6].

a)

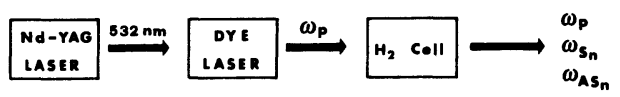

b)
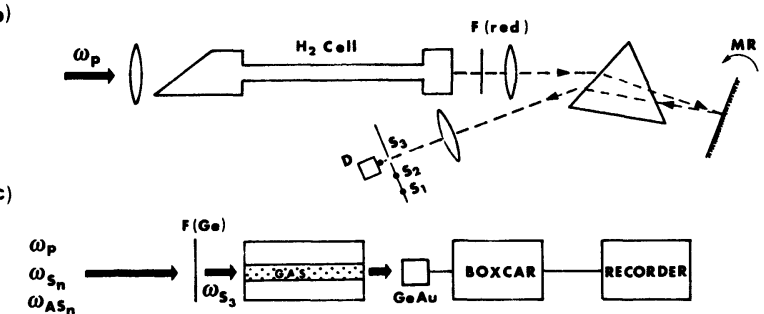

Fig. 1. - a) Block diagram of the tunable Raman laser ; b) Schematic of the experimental configuration used for the pulse energy and temporal shape measurement ; c) Diagramm of the set-up used for absorption spectroscopy of gases.
Figure $1 \mathrm{~b}$ shows the optical arrangement which we used to separate out the various Stokes (or antiStokes) components for the energy measurements. Adjustment of the rotating mirror MR behind the double pass silica prism selects the wavelength transmitted through the slit (located in the focal place of the focussing lens) onto the detector $\mathrm{D}$. The pump radiation is blocked by a coloured filter set at the exit of the Raman cell. This arrangement works for any wavelength shorter than $2.5 \mu \mathrm{m}$. For $\mathrm{S}_{3}$ measurements in the $2.5-6 \mu \mathrm{m}$ range a simple germanium filter was used as shown in figure 1c. The detector D was either a thermopile for energy measurements or a fast photodiode (RTC BPF24, rise time: $1 \mathrm{~ns})$ for time dependent pulse shape measurements.

\subsection{ChARACTERISTICS.}

2.2.1 Raman cell equipped with capillary waveguide. - The dye laser beam (P) was focussed onto the entrance bore $(1 \mathrm{~mm}$ i.d.) of the capillary tube. This 1 meter long tube made of ordinary pyrex was placed inside the hydrogen cell at about $20 \mathrm{~cm}$ from the windows. The silica lens was mounted on a precision $X-Y-Z$ translater for optimizing the input coupling. Its $40 \mathrm{~cm}$ focal length was not too far to satisfying the condition for minimum coupling losses [12]. The quality of the capillary tube allowed for a $70 \%$ transmission of the pump beam at low power level.

The output energies measured on the various Stokes beams $S_{1}, S_{2}$ and $S_{3}$ in the case of $50 \mathrm{~mJ}$ of incident pump radiation at $\lambda_{\mathrm{p}}=596 \mathrm{~nm}$ are reported in figure 2 as a function of $\mathrm{H}_{2}$ pressure in the cell. This behaviour is qualitatively the same than that reported in reference [6] for a smaller bore diameter capillary with higher transmission at slightly shorter wavelengths. In particular the energy of the $S_{2}$ beam is larger than that of the $S_{1}$ beam when $H_{2}$ pressure is above 15 bars. The maximum energy measured on the $S_{3}$ beam in these conditons $\left(0.14 \mathrm{~mJ}\right.$ at $\lambda_{S_{3}}=$ $2.32 \mu \mathrm{m}$ ) was obtained for $\mathrm{H}_{2}$ pressures ranging

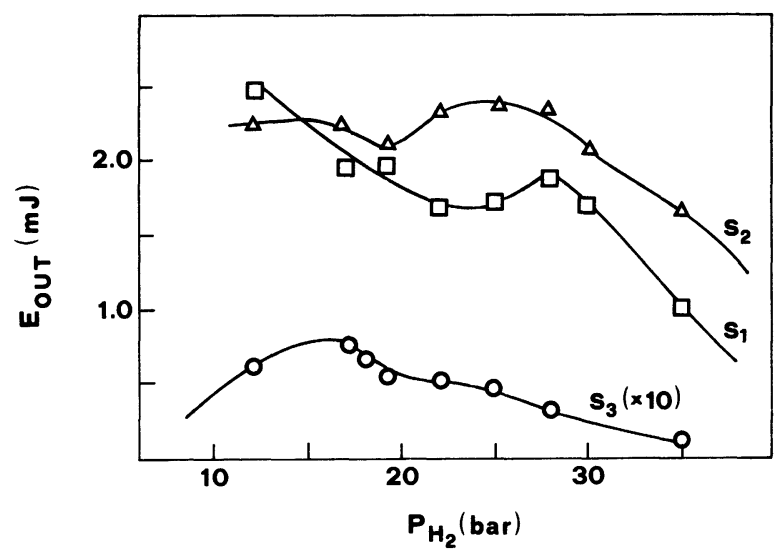

Fig. 2. - Pulse energy output on the various Stokes radiations plotted against $\mathrm{H}_{2}$ pressure in the Raman cell. Pump laser : $\lambda_{\mathrm{P}}=596 \mathrm{~nm}, E_{\mathrm{P}}=50 \mathrm{~mJ}$. 
from 12 to 17 bars (this value takes into account the energy losses of the optics, estimated to $50 \%)$. At higher incident energy $\left(E_{\mathrm{P}}=80 \mathrm{~mJ}\right)$ the maximum energy on $\mathrm{S}_{3}$, i.e. $0.5 \mathrm{~mJ}$, was obtained at 25 bars. This trend of $\mathrm{H}_{2}$ pressure to increase with the pump energy for peaking the $S_{3}$ conversion has also been observed at shorter wavelength : a $0.75 \mathrm{~mJ}$ output at $\lambda_{\mathrm{S}_{3}}=2.0 \mu \mathrm{m}$ in the case of $E_{\mathrm{P}}=100 \mathrm{~mJ}$ was measured with 40 bars of $\mathrm{H}_{2}$ in the cell. Taking into account the capillary transmission the energy conversion efficiency, expressed as output $\mathrm{S}_{3}$ energy reported to incident pump energy, was estimated to be $1 \%$ in these last conditions. Attempts to use a smaller bore diameter capillary tube were unsuccessful due to a rapid damage of the pyrex material.

It is important to take into account the actual time-dependent pulse shape of the various radiation fields. Figure 3 shows the shapes of the pump laser pulse (rhodamine $B$ dye) and of the Stokes beams $S_{1}$ and $S_{3}$. Clearly the pump radiation is made of essentially two 4 ns pulses separated by ca 7 ns. This double-peak character, originated from the $\mathrm{Nd}$ YAG laser is transferred to all Stokes radiations, even though there is some reduction in the individual pulse widths. But the second peak intensity relative to the first peak is larger for the Stokes beams than for the pump. It seems that there is a dip in the instantaneous pumping power density just when the Raman gain is optimum. It is highly probable that if the pumping field was sustained steadily for $10 \mathrm{~ns}$ the conversion to $S_{3}$, which takes some time to build up according to reference [6], would be more efficient. This appeals for development of pulseshape-controlled YAG lasers. In the study reported in reference [6], the pulseshape was rather smooth. Then in comparing its results with the present work one can conclude that the increase of the pumping energy improves the conversion significantly.

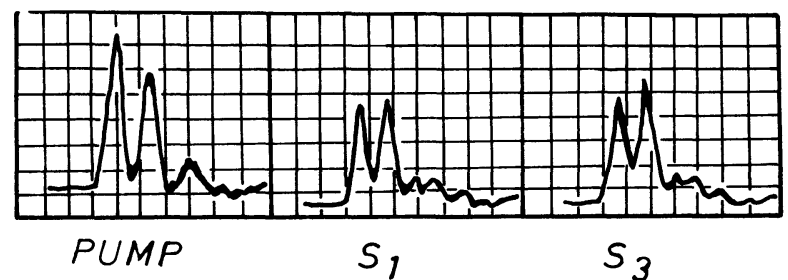

Fig. 3. - Oscilloscope traces showing the shape of the radiation pulse emitted by the dye laser (PUMP) and on the first and third Stokes beams $\left(S_{1}\right.$ and $\left.S_{3}\right)$. Scale : $5 \mathrm{~ns} / \mathrm{div}$. Rise time of the photodiode : $1 \mathrm{~ns}$. 1000 laser shots.

2.2.2 Raman cell without capillary waveguide. Energy measurements have also been done when the pyrex capillary was removed from the Raman cell. The conversion efficiency in that case was found to depend on the focussing parameters of the pump beam into the cel. The best results were obtained with a lens of $60 \mathrm{~cm}$ focal length : a $1 \mathrm{~mJ}$ output at $\lambda_{\mathrm{S}_{3}}=2.0 \mu \mathrm{m}$ was measured for $E_{\mathrm{P}}=100 \mathrm{~mJ}$ and $P_{\mathrm{H}_{2}}=12$ bars. When the focussing was tighter the amount of back-scattered Stokes radiation was larger, which depleted the forward scattering. A longer focal length maximized the conversion to $S_{1}$ and $S_{2}$ which could both be over $10 \mathrm{~mJ}$, but the conversion to $\mathrm{S}_{3}$ was poor.

The threshold for the onset of $S_{3}$ radiation in this configuration was found to be close to $20 \mathrm{~mJ}$ at $\lambda_{\mathrm{S}_{3}}=3.0 \mu \mathrm{m}$. A $100 \mu \mathrm{J}$ output has been measured at $\lambda_{\mathrm{S}_{3}}=3.1 \mu \mathrm{m}$ with $E_{\mathrm{P}}=70 \mathrm{~mJ}$. As the laser was tuned further to the low frequency side, the available energy was found to drop (about one order of magnitude between $3 \mu \mathrm{m}$ and $5 \mu \mathrm{m}$ ) for two cumulative reasons: decreases of the conversion efficiencies of the dye itself and of the Raman processes. Simultaneously the pulse to pulse variations of the $\mathrm{S}_{3}$ output were found to increase largely.

In comparing the two configurations we must remark that the main advantage of the dielectric waveguide is to increase the interaction length which reduces the threshold for $\mathrm{S}_{3}$ conversion by the 4wave mixing mechanism. But this advantage may be partly cancelled by a low transmision due to the poor quality of the pyrex tubes. Then when a powerful dye laser is available (output energy well above the threshold), the superiority of the waveguide configuration is not obvious because of the difficulty to run the system in free of damage operation. Better quality waveguides with high transmission and high resistance to pulsed laser radiation would probably improve the results largely. In practice the use of the waveguide is advantageous to generate the longer wavelengths $(\lambda \geqslant 3.0 \mu \mathrm{m})$.

\section{Applications.}

The range of tunability of the Raman laser described in the above section and its behaviour under frequency tuning have been tested by recording absorption spectra of a few molecular species. As illustrated in figure 1c, the $S_{3}$ filtered infrared beam was sent through an absorption cell onto a gold-doped germanium detector. Its signal was processed by a boxcar integrator, the output of which being monotored by a chart-recorder while sweeping the dye laser frequency.

In figure 4 is drawn an absorption spectrum of $\mathrm{CH}_{4}\left(\nu_{3}\right)$ in the $3.4 \mu \mathrm{m}$ range, showing the $\mathrm{Q}$ branch and most of the $\mathrm{P}$ branch. The top scale is the wavelength of the dye laser pump $\lambda_{P}$ and the bottom scale is the wavenumber of the third Stokes radiation $\sigma_{\mathrm{S}_{3}}$. The absorption path length was $20 \mathrm{~cm}$ and $\mathrm{CH}_{4}$ pressure was 60 torr. During this particular scan the beam-expander of the dye laser cavity had been removed out of the beam so that the emission bandwidth was rather broad $\left(\approx 0.9 \mathrm{~cm}^{-1}\right)$. The linewidth observed in the spectrum is about $1.0 \mathrm{~cm}^{-1}$, so that it seems that there is an additional 


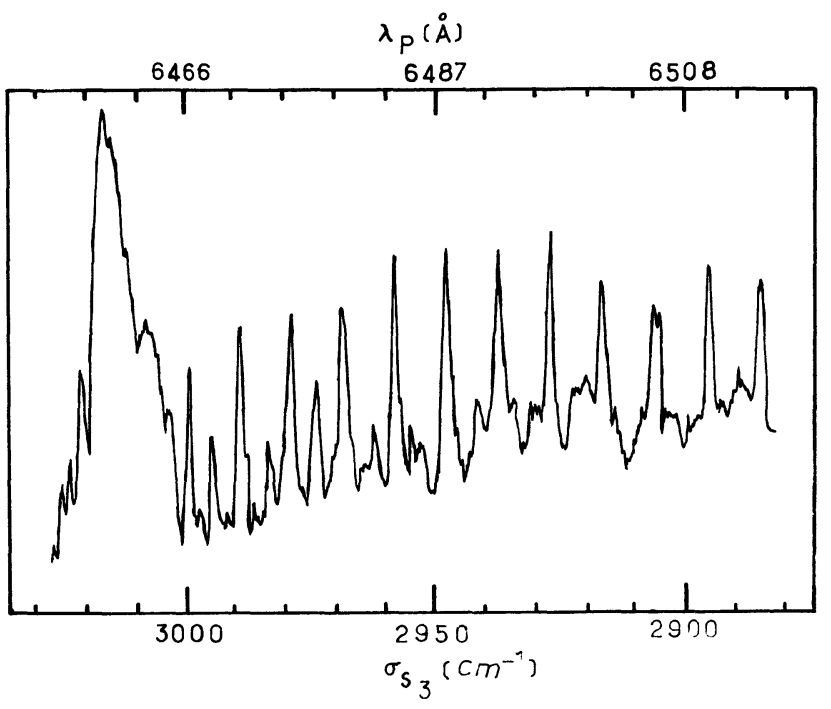

Fig. 4. - Absorption spectrum of $\mathrm{CH}_{4}\left(\nu_{3}\right)$ recorded as shown in Fig. 1c. $\mathrm{CH}_{4}$ pressure : 60 torr. Pathlength : $20 \mathrm{~cm}$. Dye laser bandwidth $\simeq 0.9 \mathrm{~cm}^{-1}$.

broadening due to the Raman processes in the hydrogen cell of about $0.1 \mathrm{~cm}^{-1}\left(\mathrm{CH}_{4}\right.$ pressurebroadening was negligible in these conditions).

Similarly a portion of the absorption spectrum of the first overtone vibration of NO is shown in figure 5 in the $2.7 \mu \mathrm{m}$ region. For this recording the absorption path length was only $25 \mathrm{~cm}$, NO pressure was 570 torr and the temperature was $290 \mathrm{~K}$. In these conditions we expect a pressure broadening contribution to the linewidth of $0.15 \mathrm{~cm}^{-1}$ [13]. The dye laser was working with the intracavity beam expander which gives an emission bandwidth of $\approx 0.15 \mathrm{~cm}^{-1}$. Each $P$ line in this spectrum (except $P$ (1.5) which has only the ${ }^{2} \pi_{1 / 2}$ component) appears as a doublet $\left({ }^{1}\right) \quad\left({ }^{2} \pi_{1 / 2}\right.$ and ${ }^{2} \pi_{3 / 2}$ components $)$ whose separation increases with $J$, as well known [14]. It is helpful to derive the effective resolution which we estimated to be $0.4-0.5 \mathrm{~cm}^{-1}$.

This is consistent with an additional broadening due to the Raman processes of $0.15-0.20 \mathrm{~cm}^{-1}$. It is also consistent with other spectra of $\mathrm{CO}$ first overtone which gave linewidths of $\approx 0.35 \mathrm{~cm}^{-1}$.

As a final example, figure 6 shows two absorption spectra of NO dimer and clusters in the $5.6 \mu \mathrm{m}$ region, realized under the following conditions. The $25 \mathrm{~cm}$ long cryogenic cell described in reference [15], initially filled with pure NO, was cooled down thanks to a jacket containing liquid nitrogen in equilibrium with its pressurized vapour. At 15 bars of $\mathrm{N}_{2}$ pressure the equilibrium temperature was $110 \mathrm{~K}$. The upper trace was recorded at slightly higher temperature, the pressure was 550 torr. The lower trace was recorded at slightly lower tempera-

(1) Lineshapes of $P(8.5)$ and $P$ (9.5) doublets are affected by atmospheric water vapor absorption.

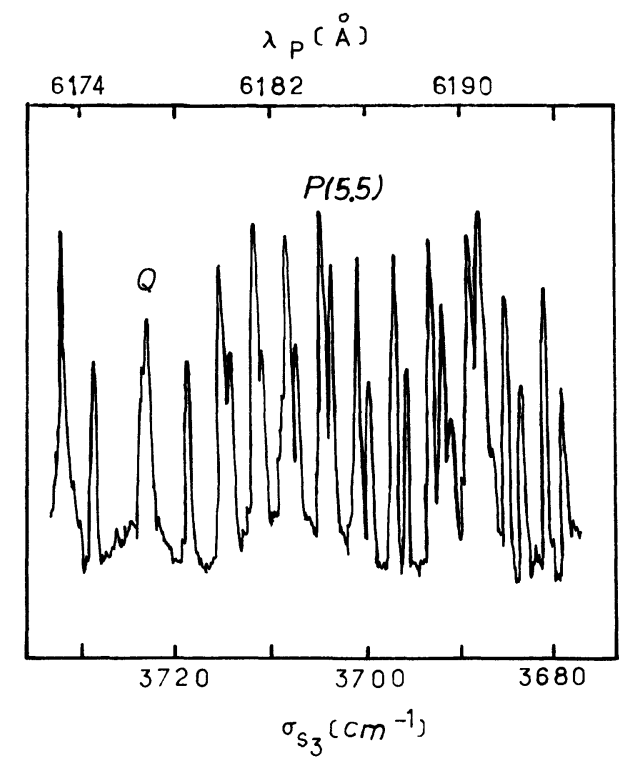

Fig. 5. - Absorption spectrum of NO (2-0). Pressure : 570 torr. Pathlength : $25 \mathrm{~cm}$. Dye laser bandwidth $\simeq 0.15 \mathrm{~cm}^{-1}$.

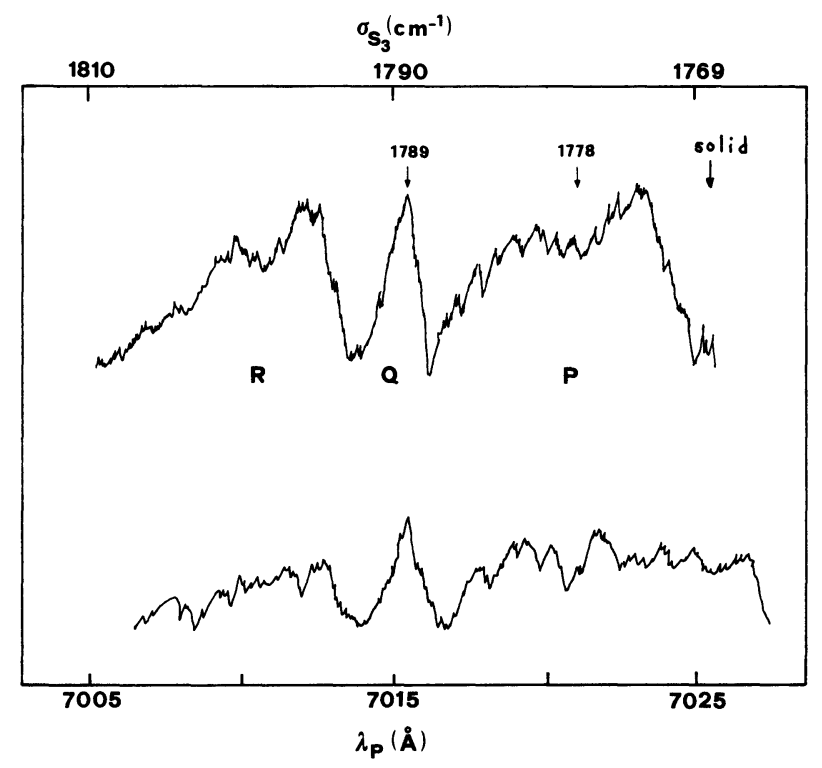

Fig. 6. - Absorption spectrum of the vapor above liquid NO. The PQR pattern is due to the dimer (NO $)_{2}$. The 1768 arrow is located at the position of the band-head of (NO ) 2 spectrum. The 1768 arrow is located at the peak of solid NO absorption. Upper trace : $P=550$ torr, $T \geqslant 110 \mathrm{~K}$; Lower trace : $P=450$ torr, $T \leqslant 110 \mathrm{~K}$.

ture, the pressure was 450 torr. The carriers of those spectra are nitric oxyde polymers present in the vapour above the liquid NO, particularly the dimer $(\mathrm{NO})_{2}$. Indeed we characterized the $\nu_{4}$ absorption spectrum of $(\mathrm{NO})_{2}$ in an earlier study [16]. It exhibits a clear band-head formation in the P-branch at $1778 \mathrm{~cm}^{-1}$. Then the absorption taking place to the red of this value, already present in our previous 
work but very weak, must be attributed to larger clusters. Indeed in the low temperature trace this absorption extends further to the red.

\section{Conclusion.}

We have shown that the tunability of a pulsed NdYAG pumped dye laser in the visible can quite easily be transferred to the mid-infrared range of the spectrum by making use of a molecular hydrogen Raman shifter. Although previous studies have reported better performances for some characteristics like the peak power output, the linewidth or the range of tunability, the presently described Raman laser offers a very good compromise of all the characteristics including the repetition rate and the simplicity. Also the relatively high energy of the pump laser pulses allows the system to work without capillary waveguide which is valuable for reliable daily operation. The effective linewidth of the infrared radiation has been inferred from specific spectroscopic applications.

Due to its basically unlimited range of tunability (so far up to $\lambda=6 \mu \mathrm{m}$ ) joined to a reasonably high resolution, and to its high peak power capability, this kind of tunable infrared laser is certainly devoted to a wide use for many chemical physics applications in which molecular vibrations have to be excited or probed.

\section{Acknowledgments.}

The authors wish to than F. Pradère and R. Frey for their valuable advice in the preparation of this work.

\section{References}

[1] SMIth, R. G., in Lasers, A. K. Levine and A. J. De Maria, eds (Dekker, New York) 1976, p. 189307 ; R. L. Byer and R. L. Herbst, Y. R. Shen, ed. (Springer, New York), 1977, p. 81-137 ; RASKer, M. J. and TANG, C. L., J. Opt. Soc. Am. B 2 (1985) 691.

[2] Welling, H. et al, Laser Spectroscopy III, (Springer) 1977, p. 370 ; Mollenauer, L. F., Quantum Electronics Pt B, C. L. Tang (ed), (Academic Press, New York) 1979, p. 1-54.

[3] SCHMIDT, W. and APPT, W., Z. Naturforsch. 27 (1972) 1373.

[4] Bierry, M., Frey, R. and Pradère, F., Rev. Sci. Instrum. 48 (1977) 733.

[5] De Martino, A., Frey R. and Pradère, F., IEEE QE 16 (1980) 1184

[6] Hartig, W. and Schmidt, W., Appl. Phys. 18 (1979) 235.

[7] Copeland, R. A. and Crim, F. F., J. Chem. Phys. 78 (1983) 5551.
[8] Robinson, J. M., Pearson, D. J., Copeland, R. A. and Crim, F. F., J. Chem. Phys. 82 (1985) 780.

[9] Frey, R., Pradère, F. and Ducuing, J., Opt. Commun. 18 (1976) 204.

[10] RabinOWitz, P., Stein, A., BRickMAN R. and KAlDOR, A., Opt. Lett. 3 (1978) 147.

[11] RabinOwitZ, P., KALDOR, A., BRICKMAN, R. and SCHMIDT, W., Appl. Opt. 15 (1976) 2005

[12] Kogelnik, H., Li, T., Appl. Opt. 5 (1966) 1550.

[13] Houdeau, J. P., Boulet, C., Bonamy, J., Khayar and Guelachvili, G., J. Chem. Phys. 79 (1983) 1634.

[14] Amiot, C. and Verges, J., J. Mol. Spectros. 81 (1980) 424.

[15] Picard-Bersellini, A. Charneau R. and BréchiGNAC, Ph., J. Chem. Phys. 78 (1983) 5900.

[16] Brèchignac, Ph., De Benedictis, S., HalbersTADT, N., Whitaker, B. J. and AVRILliER, S. J. Chem. Phys. 83 (1985) 2064. 